\title{
HANS-GEORG GADAMER: DE PRAKTISCHE OPGAVE VAN DE HERMENEUTIEK
}

\author{
Marc Van den Bossche \\ (postdoctoraal onderzoeker van het FWO)
}

Met het werk van Martin Heidegger heeft de hermeneutische filosofie een beslissende gedaantewisseling ondergaan. Voortaan was de mens zelf een hermeneutisch wezen: hij bevindt zich verstaand en uitleggend in de wereld. Met deze verandering gaat een heel nieuwe ontologische dimensie gepaard. Het zijnde, of de mens zelf, is nu interpreteerbaar geworden en is niet langer een op voorhand vaststaand gegeven: existentie gaat boven essentie. De ene werkelijkheid van de klassieke ontologie en wetenschap lijkt te zijn uiteengespat in een veelheid van perspectieven en wereldbeschouwingen.

Heel anders dan Heidegger heeft zijn leerling Hans-Georg Gadamer hier conclusies uit getrokken voor de praktische filosofie, die altijd ook een politieke filosofie is. In mijn uiteenzetting wil ik dit vaak onderbelichte aspect van de gadameriaanse hermeneutische filosofie in de schijnwerpers stellen. Na een korte schets van de hermeneutiek vóór Gadamer en van zijn plaats in die beweging, zal ik trachten te tonen waarom voor hem de reikwijdte van de methode moet ingeperkt worden. Vervolgens toon ik hoe Gadamer pleit voor een niet-methodisch denken van de praxis, waarmee hij op een originele manier verder gaat dan Heidegger en eigenlijk een hiaat vult in diens denken.

\section{Kleine historiek}

Vanaf Schleiermacher wordt de reikwijdte van het hermeneutische vragen sterk uitgebreid. Het probleem is niet langer hoe we de bijbel of andere klassieke teksten moeten verstaan, maar hoe we betekenis kunnen begrijpen: wat zijn de methoden die een objectief verstaan van teksten kunnen toelaten?

Dilthey gaat vervolgens nog een stap verder. Hij stelt het probleem van een methode die een objectieve lectuur van allerlei soorten symbolische structuren mogelijk zou maken. Dat betekent dat nu ook onze handelingen, onze morele normen of onze sociale praktijken vatbaar worden voor een hermeneutisch verstaan. Dilthey meent echter dat de hermeneutiek er moet naar streven om dezelfde methodische helderheid te kunnen verkrijgen als de natuurwetenschappen. Hij aanvaardt weliswaar een onderscheid tussen geestes- en naturwetenschappen, maar toch meent hij 
dat we beide als objectieve wetenschappen moeten kunnen beschouwen. Voor de hermeneutiek houdt dat in dat we dienen uit te gaan van een neutraal verstaan van de menselijke fenomenen, dat bijgevolg ook toegankelijk zou zijn voor alle interpretatoren, onafhankelijk van hun historische of culturele context. Uit het verdere verloop van mijn betoog zal blijken dat hier een hemelsbrede kloof ligt met het denken van Gadamer en dat voor deze laatste praxis juist moet gedefinieerd worden in tegenstelling tot dit methodische objectivisme. Dilthey mocht een onderscheid tussen geestes- en natuurwetenschappen vooropstellen, de praktijk draaide er toch op uit dat de geesteswetenschappenlijke methode de vorm moest aannemen van de natuurwetenschappenlijke. Elke subjectieve dimensie wordt er uitgesloten en bovendien heeft de hermeneuticus van daaruit geen oog meer voor het verschil tussen het verstaan van zin of betekenis enerzijds en het verklaren van verschijnselen anderzijds.

Over Hans-Georg Gadamer kan men terecht beweren dat nu juist het verzet tegen dit methodische interpreteren van de hermeneutiek de belangrijkste bekommernis doorheen heel zijn werk is. Voor hem kan hermeneutiek geen discours over de methode van objectief verstaan meer zijn. Dat verstaan is immers altijd contextueel gebonden en is in een traditie geworteld. Volgens Gadamer stemmen geschiedenis en sociale wetenschappen niet overeen met de logica van de natuurwetenschappen, omdat het interpreterende verstaan er zelf een rol in speelt: subject en object zijn er niet te scheiden. Verstaan wat een gegeven handeling of overtuiging is, gaat vooraf aan het verklaren waarom ze zich voordoet. Dit houdt in dat men een situatie moet 'lezen', wat betekent dat we de handelingen of overtuigingen moeten plaatsen in de context waartoe ze behoren en dat we ze pas kunnen verstaan in het licht van andere handelingen of gedachten. Voor Gadamer is het hermeneutische verstaan er dan ook aan gewijd de voorwaarden te onderzoeken voor het verstaan van zin.

Het inzicht in de historiciteit van ons verstaan en de nadruk op de ontoereikendheid van de wetenschappelijke methode daarvoor, maken Gadamer duidelijk schatplichtig aan Heidegger. Als we het hebben over het verstaan van zin gaat diens invloed echter veel verder. Bij Heidegger krijgt het hermeneutische verstaan immers een geheel nieuw karakter. Het gaat er bij hem niet langer om hoe de objectieve wereld in ons bewustzijn wordt geconstitueerd, maar wel om de vraag naar het menselijke zijn en hoe het Dasein zelf een project is en een product van interpretatie. Zo gezien is de eigenlijke vraag voor Heidegger niet hoe we het zijn kunnen verstaan, maar hoe het zijn verstaan is. Tijdens hun leven verhouden mensen zich interpreterend tot dat leven. Ze verstaan zichzelf in een onafgebroken proces van zelfinterpretatie, ervaring en herinterpretatie. Noch voor Heidegger, noch voor Gadamer is de mens hierin absoluut vrij. De mogelijkheden die men nu heeft, worden bepaald door de wijze waarop men zichzelf in het verleden geprojecteerd heeft. Deze opvatting van het verstaan als 'geworpen projectie' staat voor Gadamer centraal in de 
geesteswetenschappen. Op die manier is verstaan niet langer een wetenschappelijk begrijpen van entiteiten, maar eerder een praktisch verstaan van het eigen leven en de mogelijkheden die men heeft.

\section{Heidegger}

De invloed van Heidegger op Gadamer kunnen we in grote lijnen tot een drietal punten terugbrengen. Ten eerste is er de historiciteit van ons verstaan, ten tweede de ontoereikendheid van het technisch-wetenschappelijke-methodische kennen hiervoor en ten derde de transformatie van het verstaan van zijn naar zijn als verstaan. Gadamer heeft dus zonder twijfel veel te danken aan zijn leermeester. Toch mag opgemerkt worden dat hij nooit in diens schaduw is blijven staan, maar dat hij eigen accenten heeft gegeven aan de heideggeriaanse ideeën. Zo is Gadamer veel minder techniekvijandig ingesteld dan Heidegger. Zijn kritiek op de dominantie van de methodische wetenschap is weliswaar sterk heideggeriaans geïnspireerd, maar de motieven voor de kritiek van de twee filosofen zijn heel anders en misschien zelfs wel tegengesteld aan elkaar. Heidegger ziet techniek als het culminatiepunt van een westerse metafysica en humanisme, die het zijn reduceren tot een middel voor menselijke doelen. Terwijl bij Heidegger dit het gevolg is van een hele geschiedenis van zijnsvergetelheid sedert de oude Grieken, zal Gadamer eerder de dominantie van de methode in verband brengen met het opgeven van een humanistische traditie. Het is er Gadamer dan ook om te doen een brug te slaan naar deze vergeten humanistische traditie. Volgens hem zijn humanisme en antropocentrisme zeker niet gelijk te schakelen. Het is niet zo dat omdat we niet anders kunnen dan uitgaan van het perspectief van de mens, dat die mens ook in het centrum van het zijn moet staan. Ik citeer Jean Grondin, één van de meest competente Gadamerinterpretatoren van dit ogenblik:

Humanisme is niet hetzelfde als antropocentrisme. Eerder is het de erkenning van het feit dat wij als eindige wezens voortdurend blijven leren. En als we aannemen dat het filosofische humanisme niets anders is dan de bescheiden openheid voor waarheid die ons kan helpen onze behoeftigheid te boven te komen, dan is hermeneutiek een humanisme. ${ }^{1}$

Ruwweg kunnen we stellen dat Gadamer veel genuanceerder denkt dan zijn leermeester. Anders dan Heidegger heeft hij niet uitsluitend oog voor de massieve geschiedenis van het zijn, maar zal hij veeleer de klemtoon leggen op de particulariteit van de spelers in het grote spel van het zijn. Waar bij Heidegger een begrip als intersubjectiviteit slechts als een detail en in de marge van zijn denken aanwezig is, neemt deze thematiek bij Gadamer een heel eminente positie in. Hermeneutiek is 
voor hem immers een praktische filosofie en het denken over de praxis leidt per definitie naar een denken van het politieke en van wat Gadamer de 'maatschappelijke rede' heeft genoemd. Zoals al vermeld is deze dimensie van zijn hermeneutische filosofie eerder onderbelicht gebleven. En misschien - maar dit is slechts een hypothese - is dit zo omdat Gadamer te vaak door heideggeriaanse ogen wordt gelezen. Laten we de weg traceren die hem van het hermeneutische verstaan naar de praxis en het maatschappelijke leven heeft gebracht. Ik laat die weg hier op een negatieve wijze aanvangen, in die zin dat ik eerst wil laten zien waarom de weg van de praxis niet die van de methode kan zijn, of om het heideggeriaans te zeggen: die van het technische ontbergen.

\section{Wetenschap en methode}

Volgens Gadamer, in zijn opstel Was ist Wahrheit $?^{2}$ heeft zich met de moderne wetenschap een fundamentele breuk voltrokken met het Griekse en westerschristelijke denken. Met de moderne wetenschap heeft het methodische denken voorrang gekregen. Ondanks de veelvuldigheid aan gestalten van 'de' methode, lijkt er toch een vorm van eenheid te bespeuren in deze vorm van denken. Het kenideaal, bepaald door de methode, bestaat daarin dat we de weg van het kennen op een dergelijke manier bewust afleggen dat we hem steeds opnieuw kunnen bewandelen of volgen. "Methodos heißt 'Weg des Nachgehens", stelt Gadamer (GW II, p. 48). Steeds opnieuw gaan zoals men al gegaan is, dat is methodisch en dat ook kenmerkt het gebeuren van de wetenschap. Op die manier echter komen we noodzakelijkerwijze tot een inperking of beperking van wat aanspraak mag maken op waarheid. Als controleerbaarheid, het kunnen nagaan (Nachprüfbarkeit), uitmaakt of iets waar is of niet, dan is de maatstaf waarmee kennis gemeten wordt niet langer waarheid, maar zekerheid. Enkel wat aan het ideaal van de zekerheid beantwoordt kan nog als waarheid gelden. Deze betekenisverschuiving heeft ook Heidegger meerdere malen beklemtoond.

Het succes van de sciëntistische benadering berust in de eerste plaats op dit primaat van de methode. De methode is een objectief instrument dat zou garanderen dat de wetenschappelijke resultaten niet van de subjectieve vooroordelen van de onderzoeker afhankelijk zouden zijn. De methode spreidt stap voor stap een gestrengheid ten toon die elke andere onderzoeker, onafhankelijk van zijn of haar standpunt, kan reproduceren. Door deze afstand die gecreëerd wordt tussen subject en object zou de objectiviteit gegarandeerd moeten zijn. Hierdoor makt men ook op universaliteit aanspraak, een ander kenmerk van een technisch denken, dat nauw met de tendens tot uniformiteit samenhangt. De methode streeft naar universaliteit en zal die ook bereiken, tenzij er een fout verborgen zit in de methodologie. Gebeurt dit niet dan zijn de resultaten geldig voor iedereen. Hierin zit ook de reden vervat 
waarom kritische discussies binnen de wetenschap vaak de methodologie zelf betreffen. Denk aan het gekibbel over enquêtes, een vorm van onderzoek waar meetbaarheid voorondersteld wordt.

Belangrijk voor de methode is dus dat elke onafhankelijke onderzoeker de stappen kan herhalen van een wetenschappelijke verklaring om de geldigheid ervan te toetsen. Mathematische formules zijn hier dan ook de instrumenten bij uitstek, omdat ze niet variëren met het subject.

De methode, de onafhankelijkheid van de onderzoeker en zijn of haar individuele voorkeuren of vooroordelen, objectieve verificatie en het zoeken naar universele wetten zijn constitutief voor de wetenschappelijke aanblik die onze hele cultuur meer en meer is gaan vertonen. Dit wezen van de moderne wetenschap is voor ons hele leven bepalend geworden. Het ideaal van de verificatie en het begrenzen van het weten tot het controleerbare vindt zijn uiteindelijke vervulling in het na-maken. $V$ an daaruit is een wereld ontstaan van planning en techniek. Het is deze wereld die ons getoond wordt door life style-magazines: 'doe dit dan en dan, zo en zo, en je beantwoordt aan het model dat nu in is. Dat geldt voor iedereen, je kan het bewonderde model, het begeerde leven, na-maken'.

Die wereld heeft ons veel voordelen opgeleverd. Uiteraard. Maar kan dat zomaar om ons begrip van de waarheid enkel daartoe te beperken? Het technowetenschappelijke model streeft naar een notie van waarheid die niet in verband staat met de menselijke Bildung, een term die voor Gadamer belangrijk is. Wat er uit een wetenschappelijke waarheid resulteert is irrelevant voor zijn validiteit als het maar kan bevestigd worden door methodische en mathematische middelen.

Maar toch, ondanks de imperialistische tendens van het methodische, technische denken, kunnen we blijven stellen dat de humanities een heel andere betekenis toekennen aan waarheid. We kunnen het hier hebben over een zin-volle waarheid, "a formative truth", noemt de reeds geciteerde Jean Grondin dat. En dat adjectief formatif heeft alle uitstaans met het Duitse Bildung. Is methodische verificatie hier van enig belang, evenals de mathematische zekerheid? Of ook: zijn universele wetten dan echt bekommerissen voor een 'humanistische' kennis? Hebben we ons ook niet de vraag te stellen naar de plek waar ons denken aanvangt, en dat geldt evenzeer voor het wetenschappelijke denken? Met andere woorden: kunnen we er genoegen mee nemen iets als waar te beschouwen enkel en alleen als het inhoudelijk correct, juist of zeker is? Vanuit de hermeneutiek kunnen we daar ontkennend op antwoorden. Er bestaat geen enkele uitspraak die men alleen en louter op haar inhoud kan beoordelen, als we haar waarheid willen vatten. Elke uitspraak is een gemotiveerde uitspraak, ze heeft vooropstellingen die niet mee uitgesproken worden. Enkel als we deze vooropstellingen mee gaan denken, kunnen we naar de waarheid peilen: Deze vooropstellingen, vooroordelen of motivaties wil de wetenschap negeren, ook al is ze er zelf door getekend. 


\section{Vragen stellen}

Als we zo een motivatie gaan 'deconstrueren', komen we uiteindelijk bij een vraag terecht. Aan elke uitspraak ligt in eerste instantie een vraag ten grondslag, de vraag die dus de motivatie voor die ene bepaalde uitspraak geeft. Als we iemand niet verstaan, dan trachten we na te gaan hoe hij of zij tot die bewering gekomen is. Welke vraag wordt er gesteld, waarop die bewering een antwoord is? Het probleem is dan of we met deze 'deconstructie', een term die Gadamer niet gebruikt, dan toch tot het eerste kunnen komen, tot die ene onherleidbare vraag. Nee, stelt Gadamer. Elke vraag is immers zelf een antwoord. We geraken hier dus verstrikt in een dialectiek van vraag en antwoord. Elke vraag is zelf al gemotiveerd. De zin ervan is nooit in de vraag zelf te ontdekken. "Das Wesen der Frage ist das Offenlegen und Offenhalten von Möglichkeiten", zegt Gadamer in Wahrheit und Methode (GW 1, p. 304). Tot het wezen van de vraag behoort ook dat ze een zin heeft. Zin betekent dan ook richting, richtings-zin. De zin van de vraag geeft de richting aan waarin we het antwoord kunnen vinden. Met de vraag zelf plaatsen we al het bevraagde in een bepaald opzicht: de vraag geeft al de richting van het antwoord aan. Men begrijpe dat als we waarheid louter interpreteren als zekerheid of objectiveerbaarheid, dat we dan ook alleen maar antwoorden kunnen krijgen die aan die maatstaf beantwoorden.

Bij Gadamer vind ik de prachtige opmerking dat Plato ons, via Socrates, geleerd heeft dat vragen veel moeilijker is dan antwoorden. Als de gesprekspartners van Socrates in de dialoog de rol trachten om te draaien, dan komen ze pas in de problemen. Ze slagen er niet in om hét wapen van Socrates, de vraag, te hanteren. Voor Gadamer zit in deze gang van zaken het verschil verborgen tussen eigentlicher und uneigentlicher Rede, tussen de eigenlijke en de oneigenlijke dialoog, zou men kunnen zeggen. Wie in een gesprek enkel het gelijk krijgen nastreeft en niet het inzicht in een zaak, zal het vragen uiteraard veel eenvoudiger vinden dan het antwoorden. Voor Socrates echter moet men om te kunnen vragen ook weten, namelijk weten dat men niet weet. Door te vragen brengt men iets in de openheid. En de openheid van het gevraagde bestaat in het niet vastgelegd zijn van het antwoord. Elke vraag vereist die openheid, stelt Gadamer. Zo niet, is ze een schijnvraag en heeft ze geen vraag-zin.

Ik ga hier nu niet beweren dat de technowetenschap nooit vragen stelt. Zij doet dat wel, zij het niet in de zin van het hermeneutische vragen. In de wetenschap heeft men het over zekerheid of over precisie. Als de technowetenschap de dingen bevraagt, dan wil ze tot een precies antwoord komen en het is maar goed ook dat ze die krijgt. Is dit nu onze enige manier om de dingen te bevragen, om ze te ontbergen, om ze als waar te beschouwen? Is de precisie van een mathematische aanpak van onze levenspraxis zo groot als de precisie van het oor van een muzikant bij het stemmen van zijn instrument, vraagt Gadamer zich af. ${ }^{4}$ Bestaan er dan geen an- 
dere vormen van precisie die niet voortkomen uit het toepassen van regels of het gebruik van apparaten en stijgt die andere vorm van precisie daar niet bovenuit? Het antwoord van de hermeneutiek hierop is positief. Het gaat dan om een dialectiek van vraag en antwoord die nooit tot stilstand komt. Een kunstwerk kunnen we blijvend ondervragen. En misschien zullen we het nooit helemaal verstaan. Als we op die manier vragend naar de dingen toestappen, dan doen we dat niet om een definitief, sluitend antwoord te krijgen. Antwoorden worden opnieuw vragen die nieuwe antwoorden provoceren. Een kunstwerk kunnen we niet leegplukken, stelt Gadamer.

Ik zou dit verder willen uitbreiden, bijvoorbeeld in de richting van mens en natuur. Vooral als het om de ander, onze mede-mens, gaat, kunnen we hem of haar toch niet leegplukken. Kunnen wij beweren een ander helemaal te verstaan? Zo ja, dan zou zijn of haar andersheid eigenlijk opgeheven worden. De verwondering zou verdwijnen en plaats maken voor zekerheid. Het bevragen van de ander zou dan een schijn-vragen worden, want we kennen de antwoorden al omdat we de geijkte maatstaf in bezit menen te hebben.

Het verstaan van de ander is altijd een anders-verstaan. Daardoor wordt de ikgecentreerdheid van het subject doorbroken en vervalt de dichotomie van subject en object. Ze maakt plaats voor een intersubjectiviteit die een voortdurend wisselend spel is van vraag en antwoord. Leven is dialogisch leven voor Gadamer. En dit spel, dat het spel van de praxis is, onttrekt zich aan de methode.

\section{Praktische filosofie}

Doorheen het hele oeuvre van Gadamer staat de vraag naar de specificiteit van een praktisch weten voorop. Zijn project bestaat er mede in een brug te slaan tussen de klassieke notie van praktische filosofie en de hermeneutiek. Daarmee gepaard gaande meent hij een affiniteit te mogen vaststellen tussen interpreterende en morele handelingen. Beide stellen echter problemen in een cultuur die gedomineerd wordt door het hogergeschetste wetenschappelijk-methodische denken. Matthew Foster, een auteur die een boek heeft gewijd aan de praktische filosofie van Gadamer, schetst dit probleem als volgt:

De universalia die worden toegepast bij het praktische oordeel, worden binnen ons wetenschappelijke ethos beschouwd als onverifieerbaar, terwijl particularia gezien worden als verifieerbare feiten; want enkel wat geverifieerd wordt door de wetenschappelijke methode kan als reëel gelden binnen dit ethos. We kunnen dan ook vaststellen dat de overtuiging lijkt te bestaan dat er geen manier voorhanden is om het universele en het particuliere met elkaar te verbinden, zoals dat vereist wordt door het praktische oordeel ${ }^{5}$.

Noch in de hermeneutiek, noch in de praktische filosofie kan de Weg des 
Nachgehens voltrokken worden. Vandaar ook Gadamers optie dat de hermeneutiek in onze tijd de functie kan vervullen van de praktische filosofie, zoals Aristoteles die geformuleerd heeft. Hermeneutiek is voor Gadamer zondermeer de erfgenaam van deze oude traditie van praktische filosofie. In zijn opstel Was ist Praxis?, zegt hij letterlijk dat het de praktische rede is die zich tegen elke vorm van technische rationaliteit afzet (GW 4). Als we deze uitspraak combineren met een andere gedachte van Gadamer in dit boek, namelijk dat hermeneutiek filosofie is en dat ze als filosofie praktische filosofie is, dan wordt duidelijk dat hij deze alliantie aangaat als kritiek op het louter methodische denken.

De tegenstelling tussen praktische filosofie en hermeneutiek enerzijds en het methodische denken anderzijds, is voor Gadamer al snel één van zijn hoofdbekommernissen. Reeds in een tekst uit 1930, Praktisches Wissen (GW 5), duikt een variant van deze tegenstelling op, daar geformuleerd als het verschil tussen technè en phrónèsis. Het wezen van de technè bestaat erin de middelen om iets voort te brengen op een dergelijke manier ter beschikking te hebben en te beheersen dat de productie in zich zekerheid kan bieden. Bij dat technische weten, waar het om zekerheid gaat - de methode als Weg des Nachgehens is hier al impliciet aanwezig moeten we zoveel mogelijk vermijden wat precies in de phrónèsis vandoen is: het afwegen van mogelijkheden.

Technè is meest aanwezig, als ze het minst datgene doet waarin de phrónèsis bestaat: nog te zoeken, zich nog te beraden, zelf toe te kijken hoe iets moet gedaan worden. Haar wezen bestaat er juist in de weg van het eigen zoeken zoveel mogelijk overbodig te maken door een voorafgaand kennen van de juiste middelen (GW 5, p. 241).

De geciteerde tekst is een commentaar op Aristoteles en het is bij de Griekse filosoof dat Gadamer een vergeten dimensie van de hermeneutiek terugvindt: die van de toepassing. In Wahrheit und Methode stelt hij dat de hermeneutiek drie momenten kent: het verstaan, het uitleggen en het toepassen. Uitleggen en verstaan zijn ten zeerste met elkaar verbonden. Het uitleggen is niet iets wat achteraf bij het verstaan bijkomt, maar verstaan is altijd al uitleggen en het uitleggen is zelf de expliciete vorm van verstaan. Deze versmelting van verstaan en uitleggen heeft er echter toe geleid dat het derde moment, de toepassing, helemaal uit de samenhang van het hermeneutische gebeuren werd verdrongen. Gadamer neemt hier formeel stelling: "wij menen (...) dat het toepassen evenzeer een integrerend bestanddeel van het hermeneutische gebeuren is als het verstaan en het uitleggen" (GW 1, p. 313). In een voetnoot hierbij merkt hij nog op dat deze duidelijke uitspraak spijtig genoeg vaak geignoreerd wordt in de hermeneutische discussie. De samenhang van die drie hermeneutische momenten was er vroeger wel, omdat toen filologische, theologische 
en juridische hermeneutiek nog bij elkaar hoorden.

Om die drie momenten opnieuw te kunnen samenbrengen, wijst Gadamer op de hermeneutische actualiteit van Aristoteles.

Als het hermeneutische probleem er vooral in bestaat dat de overlevering in haar eigenheid wordt gelaten en toch anders verstaan moet worden, dan gaat het hier - logisch gezien - om de verhouding tussen het algemene en het bijzondere. Het verstaan is dan een speciaal geval van de toepassing van iets algemeens op een concrete en bijzondere situatie. Zo verkrijgt de aristotelische ethiek voor ons een bijzondere betekenis.(GW 1, p. 317).

Als de mens geconfronteerd wordt met de vraag naar het goede in een concrete situatie, dan bestaat een zedelijk weten erin dat in een concrete situatie het individu inziet wat van hem wordt verlangd. Anders uitgedrukt: de persoon in kwestie moet in die ene concrete situatie inzien wat van hem in het algemeen verwacht wordt. Negatief geformuleerd, betekent dit dan dat een algemeen weten dat zich niet kan laten toepassen in een concrete situatie, zinloos blijft en eigenlijk de concrete eisen die van de situatie uitgaan versluiert. Gadamer wijst er op dat het toepassen van een methodisch weten hier problematisch is, maar niet alleen dat: het toepassen van de methode heeft hier zondermeer ethische implicaties. De methode zou er immers een uniformerend effect hebben en het specifieke van verschillende ethische problemen doen vervagen. Dat is de reden waarom ethiek geen technè kan zijn, maar wel phrónèsis. Technè is namelijk een weten dat we kunnen aanleren en desgewenst altijd op dezelfde manier herhalen. En in Wahrheit und Methode legt Gadamer er sterk de nadruk op dat de hermeneutiek zich afzet tegen een 'rein' weten, dat zich van het eigen zijn zou kunnen losmaken. Gadamer ziet hermeneutiek daarom ook als praktische filosofie, zoals de titel van één van zijn opstellen luidt. ${ }^{6}$ Hermeneutiek richt zich op de praxis, luidt het daar. Praxis verwijst naar de manier waarop men zijn leven voltrekt en gaat over de vrije beslissing. Hermeneutiek is veel meer dan louter een Kunstlehre, zoals de Duitse romantiek haar nog zag. Ze draagt altijd een aspect van Selbstbezug in zich, wat ook van wezenlijk belang is in de praktische fiosofie. Uiteraard blijft de hermeneutiek gaan over verstaan en uitleggen, maar Gadamer wil daar bovenop de noodzaak van de toepassing beklemtonen: het verstaan moet ook belichaamd worden. Dat de auteur eigenlijk geen dichotomie ziet van beide, blijkt uit een mooi citaat uit bovengenoemd artikel over Hermeneutik als praktische Philosophie:

Het is vervolgens zo dat het verstaan net als het handelen een waagstuk blijft en nooit de eenvoudige toepassing van algemene regels op het verstaan van gegeven uitspraken of teksten toelaat. Dit betekent verder dat het verstaan, daar waar 
het slaagt, steeds een verinnerlijking inhoudt, die als een nieuwe ervaring in het geheel van onze eigen geestelijke ervaring binnentreedt.

En nog explicieter gaat hij verder: "Verstaan is een avontuur en is zoals elk avontuur gevaarlijk" (Gadamer, 1976, p. 106).

Het hermeneutische verstaan neemt geen genoegen met wat zich aandient, met wat gezegd wordt. Altijd zal het peilen naar de motieven, naar de belangen die aan een uitspraak voorafgaan. Of anders: op welke vraag ze een antwoord is. Vandaar ook dat de hermeneutiek veel minder zekerheid kan bieden dan de methode van de natuurwetenschappen. Als dit verstaan dan als een avontuur wordt gezien, dan liggen daar volgens Gadamer ook vele mogelijkheden verborgen. Verstaan kan er dan immers toe bijdragen dat we onze menselijke ervaringen, onze zelfkennis en de horizon van onze wereld sterk gaan uitbreiden.

\section{Maatschappelijke rede}

Praxis mag dan wel over het inrichten van het eigen leven, over de verhouding van de mens tot zichzelf gaan, maar blijft daar zeker niet toe beperkt. Vanuit het denken over de praxis stapt Gadamer over naar wat hij de 'maatschappelijke rede' (gesellschaftliche Vernunft) noemt. Net als in de ethiek, wil hij hier eveneens het denken over het maatschappelijke afgrenzen van een technisch-methodisch weten.

Wat zijn dan de kenmerken van techniek, die Gadamer als nefast beschouwt voor onze maatschappelijke organisatie? In zijn essay 'Was ist Praxis? Die Bedingungen gesellschaftlicher Vernunft' (GW 4) stipt hij twee karakteristieken van een technisch omgaan met de wereld aan. De eerste zit vervat in het feit dat techniek op een vooraf gemaakt ontwerp betrokken is. Dat ontwerp schijnt als het ware een eigen leven te zijn gaan leiden. Waar vroeger, tot in de middeleeuwen, maar ook in andere culturen, de menselijke behoefte maatgevend was voor wat geproduceerd werd, lijkt het volgens Gadamer nu zo te zijn dat het artificiële meer en meer fungeert als datgene dat consumptie en behoeften creëert. De tweede karakteristiek hangt met deze evolutie samen. Door dit meer en meer artificieel worden van onze leefwereld - het vooraf gemaakte ontwerp regelt alles - doet zich een sterk verlies aan flexibiliteit voor in onze omgang met de wereld. Wie techniek gebruikt, vertrouwt zich ook aan haar toe en verliest daardoor aan vrijheid in betrekking tot het eigen handelen. Ik herinner er hier aan dat Gadamer praxis omschrijft als vrijheid van handelen.

Door de genoemde technische karakteristieken worden twee vragen in de schaduw gesteld. De eerste: voor wie wordt hier gewerkt? De tweede: in hoeverre dienen deze technische verwezenlijkingen nog ons leven? Vanuit deze verdrongen vragen komt Gadamer tot het probleem van de maatschappelljke rede. Technicise- 
ring staat onder het motto van rationalisering, onttovering, ontmythologisering en economische rentabiliteit. Techniek bepaalt zo uiteraard meer en meer ons leven en de karakteristieken ervan worden dan ook vertaald in het perspectief van de maatschappelijke organisatie. Weliswaar wordt onze maatschappij niet helemaal geregeerd door technocraten, maar toch is ons bewustzijn doordrongen geraakt van het idee dat het misschien wel mogelijk is om door planning een doelmatiger ordening en beheersing van de maatschappij te laten ontstaan. Dit, zegt Gadamer, is het ideaal van de expertenmaatschappij, waar we ons tot vakmensen richten om ontlast te worden van praktische, politieke of economische beslissingen. De expert heeft de plaats ingenomen van de vroegere handarbeider, maar deze expert zou nu ook de praktische en maatschappelijke ervaring moeten vervangen.

Wat voor Gadamer nog problematischer is, is dat deze technische omvorming van de maatschappij ook tot een technicisering van de meningsvorming leidt. Volgens hem is dit wellicht de sterkste factor in het maatschappelijke machtsspel. De moderne informatietechniek heeft mogelijkheden gecreëerd die in grote mate de keuze van informatie nodig maakt: we moeten kiezen uit het overaanbod. Elke keuze betekent echter bevoogding, gaat Gadamer pessimistisch verder. Dat kan ook niet anders, meent hij, want wie iets kiest, onthoudt zich iets anders. En kiezen we niet, dan wordt het wellicht nog erger. Het is onontkoombaar - en deze uitspraken laat ik voor de rekening van Gadamer - dat de moderne communicatiemaatschappij tot een krachtige manipulatie van het denken leidt. Hij meent - Gadamer schreef dit in 1974 - dat het nu mogelijk is geworden om de openbare mening gepland in een bepaalde richting om te buigen en zo bepaalde beslissingen te beïnvloeden. Het bezit van de informatiemiddelen is dus beslissend. Dat de informatiebehoefte van de consument hierdoor toch niet bevredigd wordt, blijkt uit de apathie van de massamaatschappij voor publieke zaken. Dit betekent dat de toenemende informatiegraad niet noodzakelijkerwijze een versterking van de maatschappelijke rede inhoudt. Dat zou dan ook een weerslag hebben op het individu. De hedendaagse mens zou, volgens Gadamer, immers te maken kunnen krijgen met identiteitsverlies. Als het individu zich afhankelijk maakt van de technisch bemiddelde levensvorm en zich tengevolge daarvan machteloos gaat voelen, dan zou hij of zij niet langer in staat zijn tot identiteitsvorming. Dat heeft dan, in de omgekeerde richting, opnieuw een diepgaande maatschappelijke uitwerking. Volgens Gadamer zit hierin een groot gevaar verscholen: de privilegiëring van het vermogen om zich aan te passen. Niet langer de creatieve vermogens van de enkeling zijn nog van tel, maar zijn aanpassingsvermogen. De maatschappij van experten zou op die manier uitgroeien tot een maatschappij van functionarissen: we moeten onszelf in stand houden als functionaris van het apparaat waarvoor we werken. Uiteindelijk zouden we dan vervallen in maatschappelijke onredelijkheid, waarbij iedereen nog slechts op het eigen functioneren gefixeerd is. 
Ondanks deze bijwijlen overdreven negatieve visie eindigt Gadamer zijn artikel over de maatschappelijke rede toch met een positieve noot, in die zin dat hij meent dat we - uit nood - (Heidegger/Hölderlin: "wo die Gefahr am höchsten ist") tot een nieuwe solidariteit zullen komen. Voor rede is het nooit te laat, stelt hij. Ook vindt hij dat we niet teveel geloof moeten hechten aan onheilsprofeten, omdat hun voorspellingen van te veel onbekenden afhangen. Hij herinnert ons aan de heisa die ooit gemaakt werd rond de eerste spoorweg. Psychiaters dachten toen ook dat onze geestelijke gezondheid zou geschaad worden door dat monster dat de trein was. Als zij gelijk hadden, dan zouden we nu allen krankzinnig moeten zijn, besluit Gadamer. Uit deze laatste zin mag men afleiden dat het met de ogenschijnlijke technofobie van Gadamer best meevalt. Toch lijkt hij met zijn kritiek op onze technische maatschappij soms in tegenspraak te komen met de vooronderstellingen van zijn eigen denken.

\section{Kritisch besluit}

Laten we Gadamers hermeneutiek letterlijk nemen en het spel van vraag en antwoord bij hem zelf 'deconstrueren'. Hij stelt zich zo de vraag in hoeverre de techniek ons leven nog dient. Het antwoord op deze vraag doet hier niet echt ter zake. Belangrijker is zich af te vragen op welk antwoord Gadamers vraag een reactie is. Dat antwoord, van hemzelf, zit vervat in het begrip 'ons leven'. Wat is dat, 'ons leven'? Is dat een entiteit die los staat van een context, dat wil zeggen, los van de technische maatschappij? Evolueert het antwoord op de vraag wat ons leven is niet mee met de maatschappij waarin dat leven geleid wordt? Trouw aan Gadamers eigen hermeneutiek moet het antwoord hierop positief zijn. Zijn vraag naar de mate waarin techniek ons leven nog dient, zou dus wel eens in tegenspraak kunnen zijn met zijn uitgangspunten en er dreigt hier bovendien een essentialisme, wat evenzeer onhoudbaar is in zijn denken. Dezelfde kritiek gaat op voor zijn vrees voor identiteitsverlies. Welke identiteit dreigt er verloren te gaan in onze technische maatschappij? Bestaat die identiteit ook hier los van de technische omgeving? Is zij onveranderlijk gegeven? Gadamers antwoord hierop moet telkens ja klinken, anders zou het totaal overbodig zijn om die vrees uit te spreken. Met dat ja gaat hij echter opnieuw in tegen zijn hermeneutisch referentiekader en tegen zijn idee dat praxis precies gaat over de eigen, vrije beslissing.

We zouden tenslotte nog kunnen opmerken dat de huidige tendens in de techniekfilosofie, die van het sociaal constructivisme, het automatisme van de techniek, waar Gadamer lijkt van uit te gaan, tegenspreekt. Techniek wordt opgebouwd vanuit de maatschappelijke rede, zouden we met zijn woorden kunnen zeggen. Maar die kritiek is wellicht overtrokken, vermits het hier grotendeels gaat om teksten van twintig jaar en meer oud. Dat verklaart ook waarom hij nog sterk gehecht blijkt te 
zijn aan een mechanistisch wereldbeeld, want in dat kader dienen we de manier te begrijpen waarop hij de methode omschrijft. De nieuwe technologie heeft een heel andere aanblik en heeft de horizon van onze wereld op een dergelijke manier verruimd, die we enkele decennia geleden onmogelijk konden voorzien.

Deze kritiek neemt niet weg dat Gadamer ons op een inspirerende manier toont hoe hermeneutiek ook om praxis vraagt en waarom deze praxis geen methode, in de klassieke mechanistische betekenis, toelaat. Hermeneutiek en praxis leren ons open te staan voor het contingente van onze existentie. Door die openheid blijven we trouw aan de rede, die ook geen onveranderlijke entiteit is. Ik besluit, mét Gadamer:

De Rationaliteit van de menselijke praxis en de rationaliteit van de praktische filosofie komen niet met het contingente in botsing, alsof dat iets totaal anders zou zijn. Zij zijn gegrond in de factiviteit van de praxis, die onze levenswerkelijkheid is - en niet in wat afgeleid wordt in het principe van een principe, zoals dat aan het logisch bewijsideaal van de wetenschap zou beantwoorden (G.W. 10, pp. 265-266).

Hebben we niet dit soort openheid en flexibiliteit nodig in onze technische samenleving?

\section{Noten}

${ }^{1} \mathrm{~J}$. Grondin, Sources of Hermeneutics, New York, SUNY Press, 1995, p. 123.

${ }^{2}$ in H.G. Gadamer, Gesammelte Werke II, Tübingen, J.C.B. Mohr, 1993. Voortaan zal ik bij citaten van Gadamer verwijzen naar GW, gevolgd door het bandnummer, tenzij het om teksten gaat die niet in de verzamelde werken zijn opgenomen. Voor een Nederlandse vertaling van dit opstel, zie: De Uil van Minerva vol. 2, nr. 1 (herfst 1985), pp. 3-15.

${ }^{3} \mathrm{~J}$. Grondin, Sources of Hermeneutics, p. 131.

${ }^{4} \mathrm{cf}$. 'Vom Wort zum Begriff', in: J. Grondin (Hg.), Gadamer Lesebuch, Tübingen, Mohr Siebeck, 1997, p. 104.

${ }^{5} \mathrm{M}$. Foster, Gadamer and Practical Philosophy. The Hermeneutics of Moral Confidence, Atlanta, Scholars Press, 1991.

${ }^{6}$ H.G. Gadamer, 'Hermeneutik als praktische Philosophie', in: Vernunft im Zeitalter der Wissenschaft, Frankfurt, Suhrkamp, 1976. 